\title{
The Effect of a Hollow Fixture on Energy Dissipation of Ultrasonic Welded Carbon Fiber/Polyamide 66 Composite
}

\author{
This study enriched the understanding of energy dissipation during \\ ultrasonic welding of polymers
}

BY Q. ZHI, X.-R. TAN, Z.-X. LIU, W.-H. LIU, Y. LIU, B.-L. OU, H.-W. ZHAO, AND P.-C. WANG

\begin{abstract}
In this study, the effect of the fixture configuration on ultrasonic welding of 4-mm-thick carbon-fiber-reinforced polyamide 66 (CF/PA66) composite with $30 \%$ mass fiber was evaluated. An analytical model to estimate the energy dissipation in the welding zone of lapped CF/PA66 samples was derived. Calculation analyses showed the energy dissipation at the faying interface of joints made from hollow-fixture ultrasonic welding (HFUSW) was about $25 \%$ higher than those made from conventional ultrasonic welding (CUSW) under the given process variables. This was primarily attributed to the almost total reflection at the workpiece-to-fixture interface in HFUSW. Experimental results indicated that the HFUSW joints exhibited a greater peak load and weld area than CUSW joints when the weld time was less than $2.1 \mathrm{~s}$. The optimal weld time for CUSW and HFUSW processes were 2.1 and $1.7 \mathrm{~s}$. When the weld time exceeded the optimal time, the joints occurred with a porous region, which was caused by thermal decomposition of the material, resulting in the decrease in peak load. Experimental and simulation results demonstrated the HFUSW process changed the propagation behavior of the ultrasonic wave and enhanced the energy dissipation at the faying interface. This study enriched the understanding of energy dissipation during ultrasonic welding of polymers.
\end{abstract}

\section{KEYWORDS}

- Ultrasonic Welding • Ultrasonic Transmission

- Energy Dissipation • Peak Load

\section{Introduction}

With the demands of automotive lightweighting and regulating energy consumption, more and more thermoplastic composites are being used in the vehicle industry because they are lightweight, cost effective for manufacturing/assem- bling, and resistant to corrosion and oxidation (Refs. 1-4). Carbon-fiber-reinforced polyamide 66 (CF/PA66) has been widely used for automotive applications, such as engine covers, intake manifolds, and radiators, because of its excellent comprehensive mechanical properties (Refs. 5-7). In this context, many eco-friendly joining techniques, such as ultrasonic welding (Refs. 8, 9), laser welding (Ref. 10), friction welding (Ref. 11), and so on, have been developed for polymer bonding. Among these, the ultrasonic welding technique receives greater emphasis because it is fast and economical and provides a good cosmetic quality (Refs. 12, 13).

For a conventional ultrasonic welding process, workpieces to be joined are placed between the horn and fixture, a clamping force is applied to the horn, and ultrasonic waves pass between the horn and fixture through the workpieces (Ref. 14). The ultrasonic energy distribution and dissipation is crucial to the weld quality (Refs. 15, 16). However, few studies in energy distribution and dissipation during ultrasonic welding have been reported. Based on classic acoustic propagation theory and other scholars (Refs. 15-17), ultrasonic welding of CF/PA66 is a process where the ultrasonic oscillations are transmitted through the horn to the workpiece and through the second workpiece to the fixture. Then the waves bounce back to the horn, and this circulation continues until the energy dissipates completely. The majority of the ultrasonic energy concentrates at the interfaces because of its high impedance (Ref. 18) and results in the melting of the materials. In a classical ultrasonic welding setup, there are three interfaces, namely the horn-toworkpiece interface (interface I), workpiece-to-workpiece interface (faying interface, interface II), and workpiece-tofixture interface (interface III), as shown in Fig. 1. Ultrasonic waves are reflected, absorbed, and transmitted at each interface (Ref. 16). The reflectivity and absorptivity of the first two interfaces are normally constant when the horn and workpieces are determined. However, the reflectivity and absorptivity of the workpiece-to-fixture interface could be changed easily by changing the fixture configuration. In 


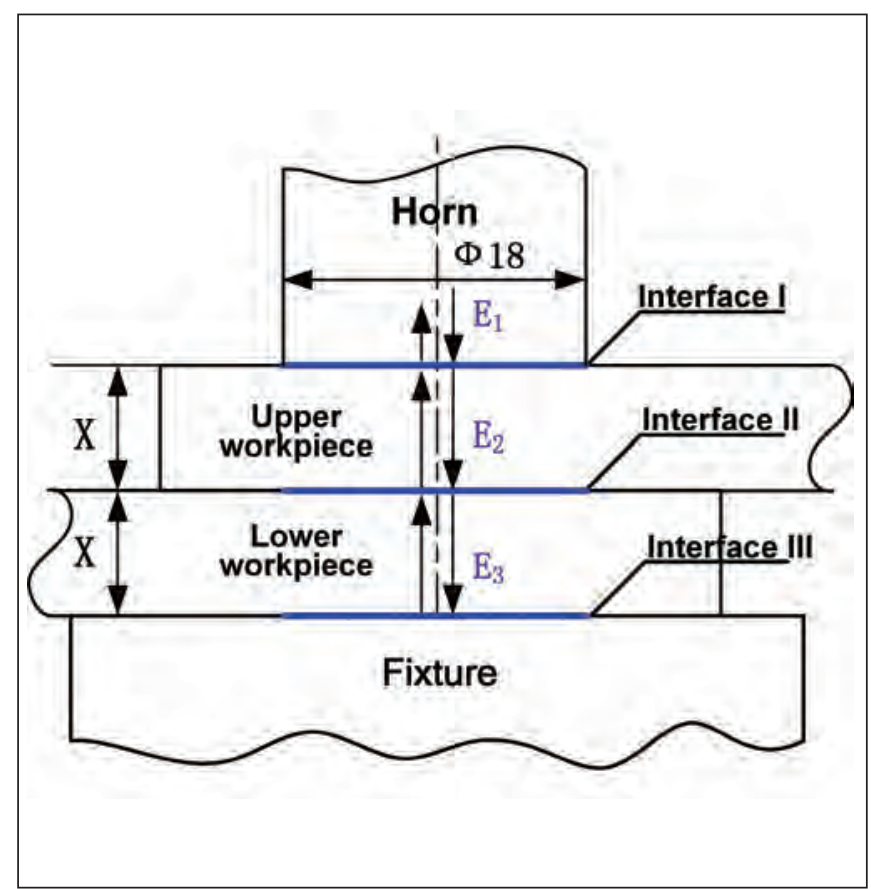

Fig. 1 - Schematic of ultrasonic wave transmission during the ultrasonic welding process.

theory, the smaller the transmissivity (which means larger reflectivity) at interface III, the higher the energy efficiency of the ultrasonic welding process. The reflectivity at interfaces can be calculated by the following equation (Ref. 19):

$$
\gamma=\left|\frac{\rho_{i} c_{i}-\rho_{j} c_{j}}{\rho_{i} c_{i}+\rho_{j} c_{j}}\right|
$$

where $\rho_{i}, \rho_{j}$ and $c_{i}, c_{j}$ are the densities and sound velocities of materials at each interface. It can be inferred that the reflectivity can be improved by increasing the difference between $\rho_{i} c_{i}$ and $\rho_{j} c_{j}$. Therefore, if the workpiece-to-fixture interface changes to a workpiece-to-air interface (i.e., the fixture is substituted by air), the reflectivity at interface III would reach its maximum (close to $100 \%$, due to the small density of air). As a result, ultrasonic welding with a hollow fixture, shown in Fig. 2, was proposed. To distinguish it from conventional ultrasonic welding (CUSW), it was defined as hollow-fixture ultrasonic welding (HFUSW).

For HFUSW, an opening with dimensions of $19 \mathrm{~mm} \times 38$ $\mathrm{mm} \times 2 \mathrm{~mm}$ was spaced between the bottom surface of the lower workpiece and fixture, as shown in Fig. 2B. The ultrasonic vibrations were conducted to the horn, the ultrasonic waves transmitted through the workpiece to the second workpiece, and then almost all the waves bounced back to the workpieces directly. This behavior was different from CUSW where the ultrasonic waves transmit through the workpieces to the backup fixture that underlies the second workpiece. Whether the difference in ultrasonic transmission would affect energy dissipation at the faying interface was a major concern.

In this study, an analytical model in view of ultrasonic wave transmission was proposed and formulated to clarify the difference in energy dissipation at the faying interface. Then the 4-mm-thick lapped CF/PA66 composite specimens were fabricated using HFUSW and compared with those made with CUSW.

\section{Experimental Procedure}

\section{CF/PA66 Composite}

Commercial polyamide 66 and carbon fiber $(24 \mathrm{~K}, \mathrm{~T} 300$ type, Toray Carbon Magic Co. Ltd.) with a length of $2 \mathrm{~mm}$ were selected in this study. Carbon fibers were first cleaned with a concentrated solution of nitric acid and then surface pretreated using $8 \%$ diglycidyl ether of bisphenol solution in acetone. Both polyamide 66 and pretreated carbon fibers were dried at $80^{\circ} \mathrm{C}$ under vacuum condition for $3 \mathrm{~h}$. A twinscrew extruder with two separate inlets was used to mold CF/PA66. Polyamide 66 was added in the first hopper while carbon fibers were added into the second hopper. To minimize the fracture of the carbon fiber during compounding, polyamide 66 was fully melted before the carbon fibers were added. The processing temperatures were $270^{\circ} \sim 280^{\circ} \mathrm{C}$, and the screw speed was $180 \mathrm{rpm}$. After fully mixing polyamide 66 with carbon fibers in a twin-screw extruder, the CF/PA66 composite was processed into pellets with a length of $2 \mathrm{~mm}$. The pellets were then fed into the injection extruder to be molded into coupons with the dimensions of $4 \mathrm{~mm} \times 38 \mathrm{~mm}$ $\times 132 \mathrm{~mm}$. The mechanical properties of the injection-molded CF/PA66 composite with 30\% mass fiber were measured and the results are shown in Table 1.

\section{Ultrasonic Welding}

The ultrasonic welding process was performed using a KZH-2026 multifunction ultrasonic welding machine (Weihai Kaizheng Ultrasonic Technologies Co. Ltd., China) with a nominal power of $2.6 \mathrm{~kW}$, nominal frequency of $20 \mathrm{kHz}$, and nominal amplitude of $25 \mu \mathrm{m}$. The final horn displacement, weld energy, weld time, horn pressure, hold time, and delay time were displayed in the control panel after the ultrasonic welding process. The machine had three welding modes, namely energy, time, and collapse modes. The values of weld energy, weld time, and horn displacement for the three modes, respectively, were preset to control the welding process. In this study, time

Table 1-Mechanical Properties of Molded 4-mm-Thick CF/PA66 Composite Coupons with 30\% Mass Carbon Fiber

\begin{tabular}{ccccc} 
& $\begin{array}{c}\text { Tensile Strength } \\
(\mathrm{MPa})\end{array}$ & $\begin{array}{c}\text { Standard Deviation } \\
(\mathrm{MPa})\end{array}$ & $\begin{array}{c}\text { Elastic Modulus } \\
(\mathrm{MPa})\end{array}$ & $\begin{array}{c}\text { Standard Deviation } \\
(\mathrm{MPa})\end{array}$ \\
\hline PA66 & 78 & 2 & 2901 & 210 \\
CF/PA66 & 99.2 & 3 & 8936 & 421 \\
\hline
\end{tabular}


A

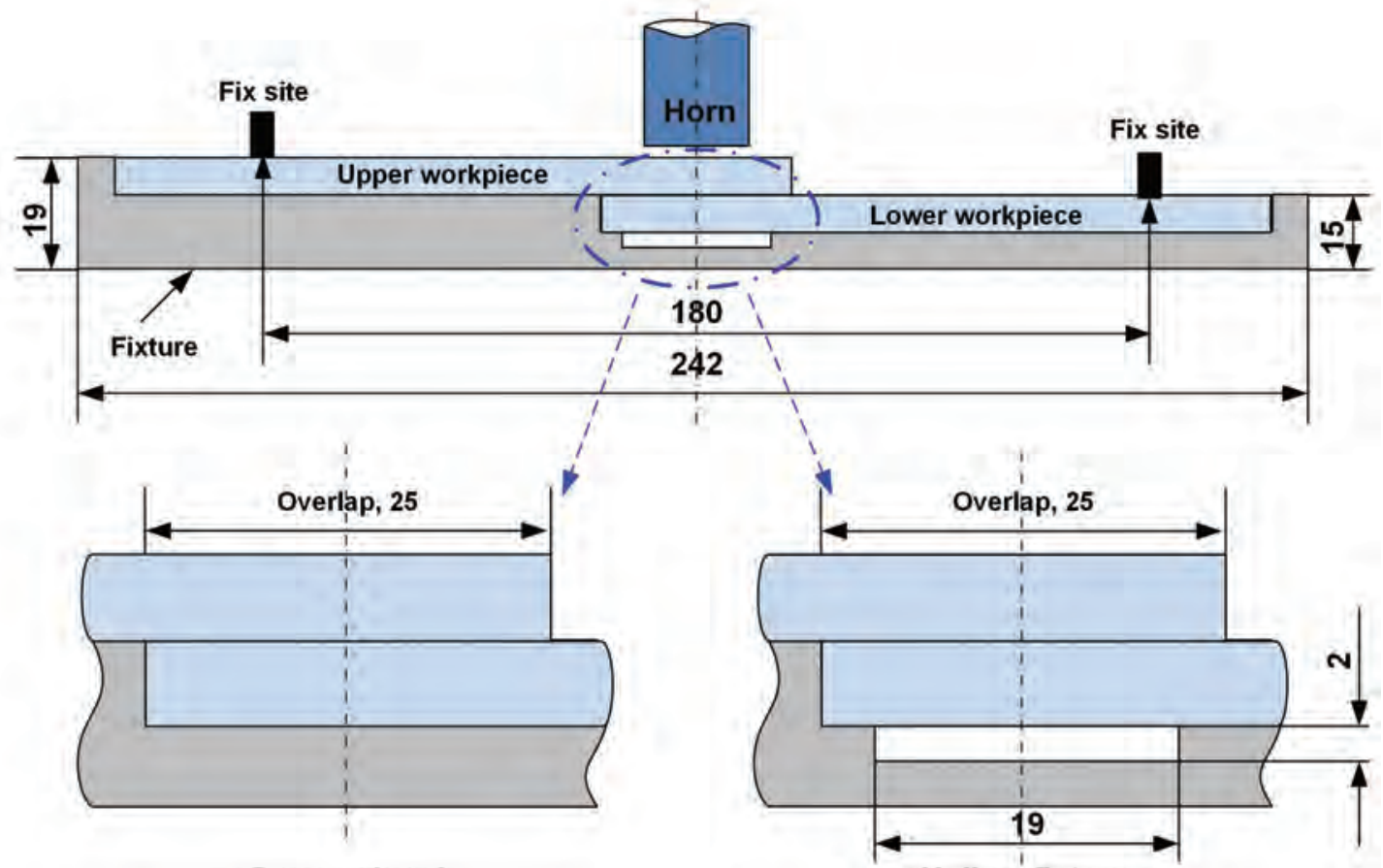

Conventional

Hollow fixture

C

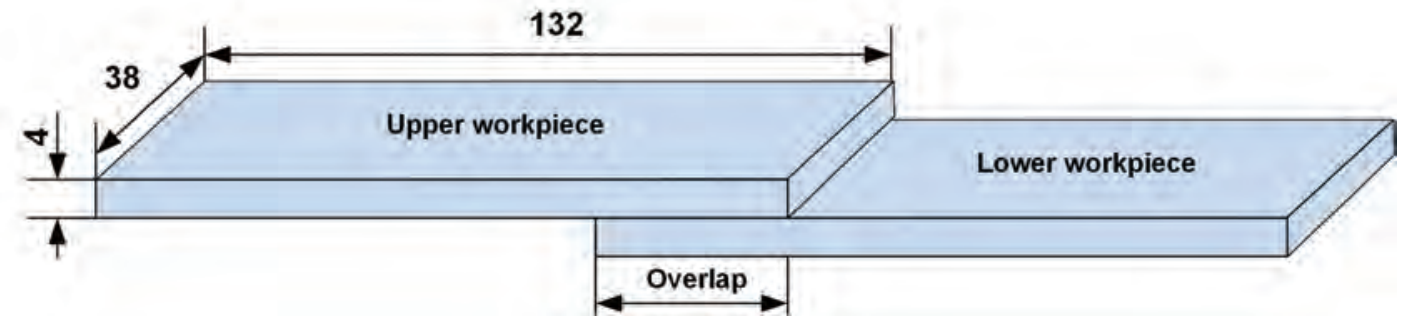

Fig. 2 - Schematic for the following: A - Hollow-fixture ultrasonic welding of carbon fiber/polyamide 66; B - the conventional and hollow fixtures; $\mathrm{C}-\mathrm{a}$ lap-shear specimen (dimensions in $\mathrm{mm}$ ).

mode was selected and the values of the delay time, weld force, hold time, and ultrasonic time were preset prior to welding. The lapped joints were welded with different fixture configurations as shown in Fig. 2B, and three replicates were welded per condition. All specimens were welded using a 7075 aluminum horn with a diameter of $18 \mathrm{~mm}$.

\section{Quasi-Static Test}

Quasi-static tests were performed by loading each specimen to failure in an MTS 810 tensile tester (MTS Systems Corp.) according to ASTM D1002-2001 Standard Test Method for Apparent Shear Strength of Single-Lap-Joint Adhesively Bonded Metal Specimens by Tension Loading (Metal-toMetal). To minimize the bending stresses inherent in the testing of single-lap weld specimens, filler plates were attached to both ends of the specimen using masking tape to accommodate the sample offset. The performance of the joint was evaluated by the peak load. Three replicates were performed, and the average peak loads were reported.

\section{Temperature Measurement}

To compare ultrasonic energy dissipation during HFUSW and CUSW, the temperature evolution near the faying surface was measured. Figure 3 shows the experimental setup for temperature measurement. As shown, a small hole with a diameter of $1.0 \mathrm{~mm}$ and a depth of $12.5 \mathrm{~mm}$ was drilled at $0.2 \mathrm{~mm}$ from the bottom surface of the upper workpiece. A K-type thermocouple was imbedded into the small hole and secured with an epoxy compound. The temperature evolution was recorded as a function of time by a data acquisition system during the ultrasonic welding.

\section{FTIR Spectroscopy}

The chemical structure of the polymer was characterized with a Fourier-transform infrared spectroscopy (FTIR) (PerkinElmer Spectrum ${ }^{\text {TM }}$ One FTIR). Pellets made of $\mathrm{CF} / \mathrm{PA} 66$ powder were diluted in $\mathrm{KBr}$, and the FTIR spectra 


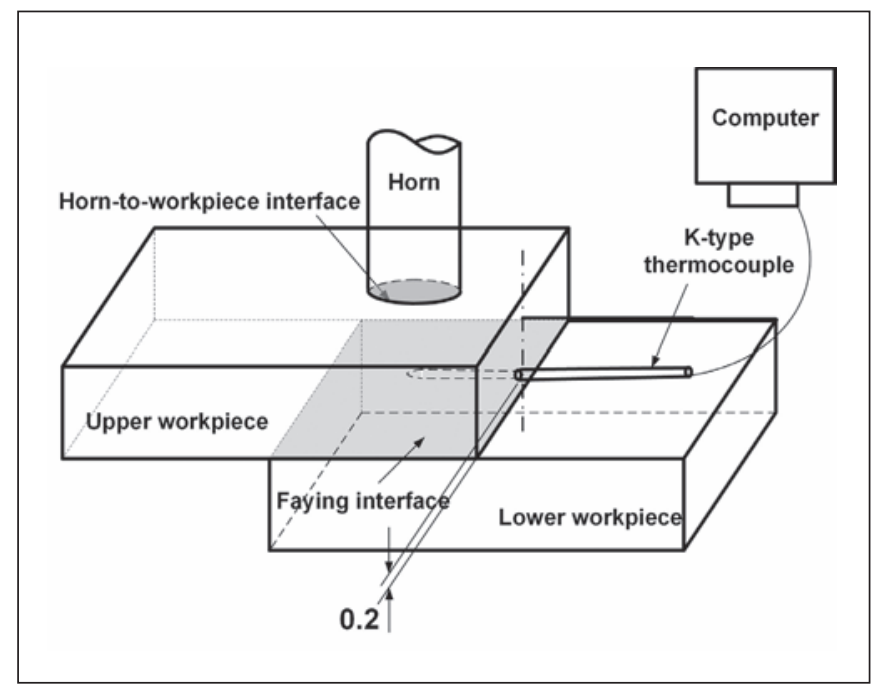

Fig. 3-Schematic of the temperature measurement during the ultrasonic welding of the carbon fiber/polyamide 66 composite (dimensions in $\mathrm{mm}$ ).

were recorded between the 4000 and $400 \mathrm{~cm}^{-1}$ range. The powder was obtained by grinding with an agate mortar and pestle under an infrared lamp.

\section{Results and Discussion}

\section{Ultrasonic Wave Transmission Behavior in Ultrasonic Welding}

The weld quality of a joint is closely related with the ultrasonic wave transmission behavior during the welding process (Refs. 15, 16). An ultrasonic transmission model based on Khmelev's research (Ref. 15) was built, as illustrated in Fig. 1. The upper and lower workpieces were perpendicular to a horn and supported by a fixture. During the welding process, ultrasonic waves propagated from the horn to the upper and lower workpieces and then bounced back to the horn and top surface of the upper workpiece. The ultrasonic waves propagated from the horn and bounced back to the horn were defined as a cycle. The ultrasonic waves attenuated during the travelling, and the surplus ultrasonic energy propagated to the workpieces and reflected to interface I again. The propagation continued until the waves attenuated completely.

Since the impedance at the contact interfaces was the largest, most of the energy dissipated at the interfaces and the rest dissipated by the workpieces (Ref. 18). Though a portion of ultrasonic oscillations dissipated at interfaces I and III, the vibration heating dissipated quickly due to the excellent thermal conductivity of the horn (aluminum) and fixture (steel), as well as the weld formed at the interface between the upper and lower workpieces (interface II) (Ref. 20). Consequently, the temperature at interface II was the highest, and the energy dissipated at interface II influenced the weld quality.

For CUSW, there were three interfaces, and the absorption, reflection, and transmission coefficients at each interface are defined as $\alpha, \gamma$, and T. At each interface, these coef-

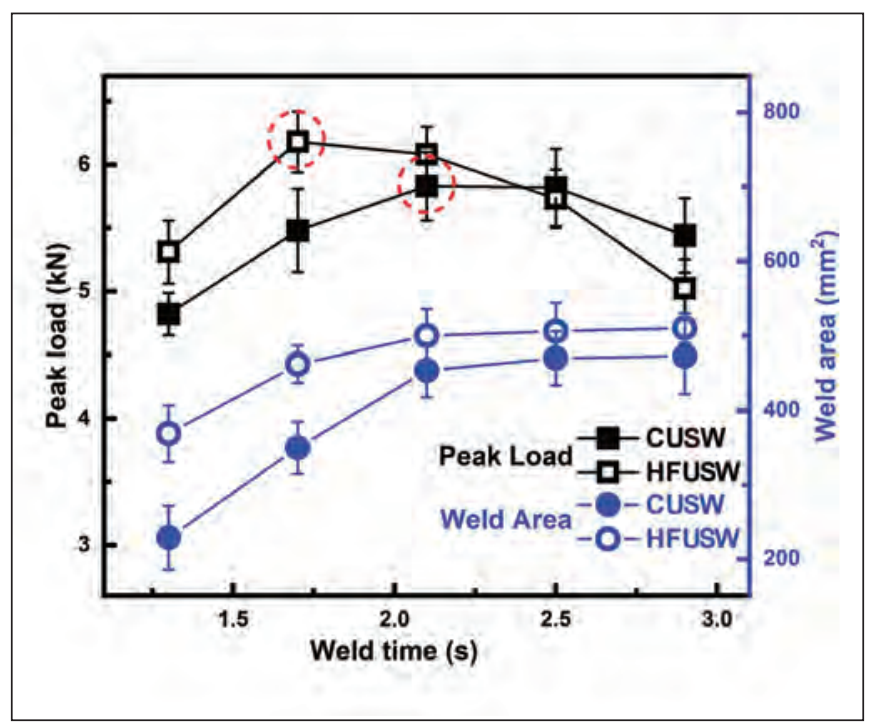

Fig. 4 - Effect of weld time on the peak load and weld area of CUSW and HFUSW joints.

ficients satisfy the equation $\alpha+\gamma+T=1$ (Ref. 16). The friction coefficients and pressures at interfaces, I and II are similar, thus the absorption coefficient is assumed to be the same (Ref. 16), namely $\alpha_{1}=\alpha_{2}=\alpha=0.16$ (the value of $\alpha$ was calculated in our previous study, Ref. 16). The power of the welding machine (output energy per unit time) was defined as $\mathrm{P}(2600 \mathrm{~W})$, while $\mathrm{S}$ was the area of the horn ( 254.5 $\mathrm{mm}^{2}$ ). The dissipated energy per unit area per unit time, $E_{0}$, is the ratio of $\mathrm{P} / \mathrm{S}$. The energy conducted into interfaces I, II, and III in the first cycle can be expressed as follows:

$$
\begin{gathered}
E_{1}=E_{0} T_{1} \\
E_{2}=E_{0} T_{1} e^{-2 \lambda X} \\
E_{3}=E_{0} T_{1} T_{2} e^{-4 \lambda X}
\end{gathered}
$$

where $X$ is the thickness of the workpiece, $4 \mathrm{~mm}$; $\lambda$ is the damping factor on the amplitude of the welding machine (0.37, Ref. 16); and $e^{-2 \lambda X}$ and $e^{-4 \lambda X}$ are the damping factors of the weld energy within the upper and lower workpieces. The reflected waves at interface III conducted into interfaces II and I, as shown in Fig. 1. Then the energy absorbed at interface II in the first cycle is as follows:

$E_{2-f c}=E_{0} T_{1} \alpha e^{-2 \lambda X}+E_{0} T_{1} T_{2} \gamma_{3} \alpha e^{-6 \lambda X}=E_{0} T_{1} \alpha\left(e^{-2 \lambda X}+T_{2} \gamma_{3} e^{-6 \lambda X}\right)$

The energy absorptivity at interface II within one cycle could be described as the following:

$$
\begin{aligned}
& K=\frac{E_{2=f c}}{E_{1}}=\frac{E_{0} T_{1} \alpha\left(e^{=2 \lambda X}+T_{2} \gamma_{3} e^{=6 \lambda X}\right)}{E_{0} T_{1}} \\
& =\alpha\left(e^{-2 \lambda X}+T_{2} \gamma_{3} e^{=6 \lambda X}\right)
\end{aligned}
$$

After the first propagation cycle, the surplus energy at interface I, which also was the energy for the second cycle, is expressed as follows: 


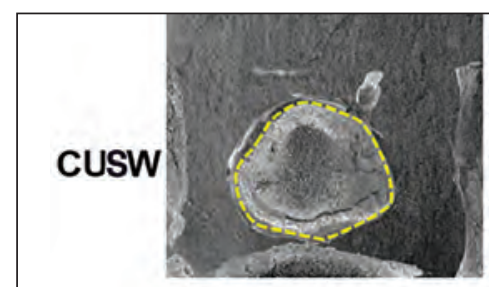

$1.3 \mathrm{~s}$

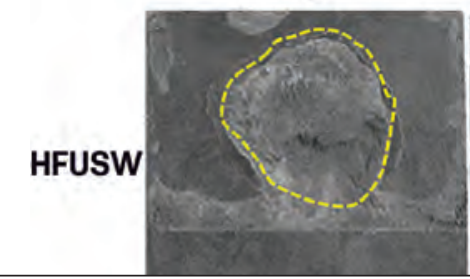

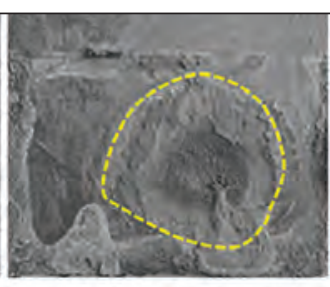

$1.7 \mathrm{~s}$

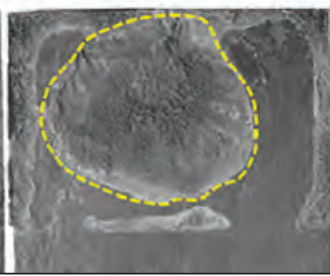

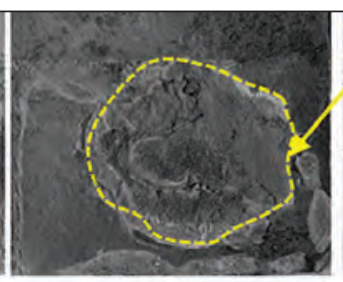

2.1s

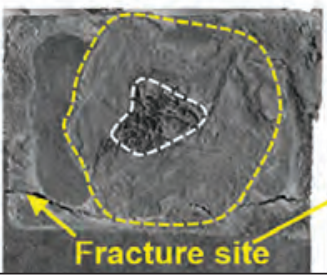

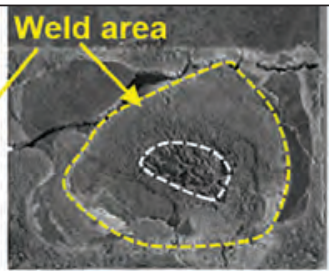

$2.5 \mathrm{~s}$

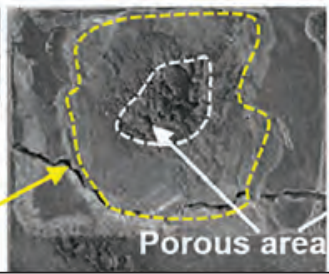

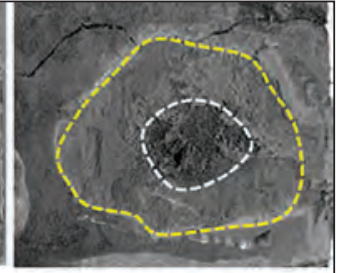

2.9s

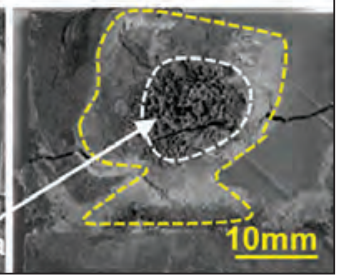

Fig. 5 - Fracture surfaces of the CUSW and HFUSW 4-mm-thick shear lap carbon fiber/polyamide 66 composite.

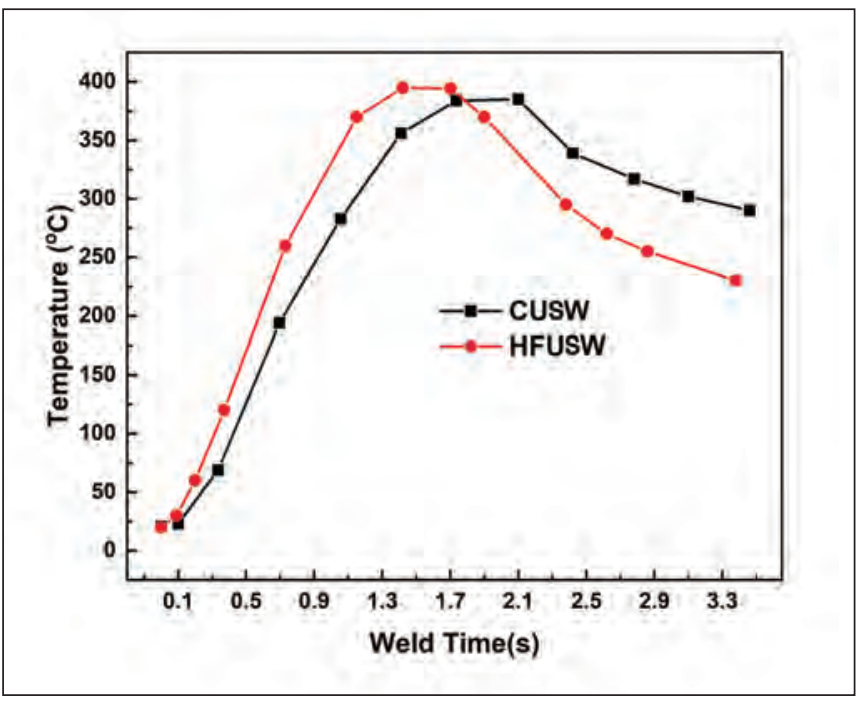

Fig. 6 - Temperature-time histories near the faying surfaces for CUSW and HFUSW joints fabricated with their optimal weld time.

$$
E_{2-1}=E_{0} T_{1} e^{-8 \lambda x} T_{2}^{2} \gamma_{1} \gamma_{3}
$$

$\gamma_{1}$ and $\gamma_{3}$ are the reflection coefficients at interface I and III, which can be estimated by Equation 1 . The densities and sound velocities of the horn, $\mathrm{CF} / \mathrm{PA} 66$, fixture, and air were $2.81,1.22,7.85,1.29 \times 10^{-3} \mathrm{~g} / \mathrm{cm}^{3}$ and $5000,2591,5200$, $340 \mathrm{~m} / \mathrm{s}$, respectively.

The ratio of the surplus energy to the initial energy at interface I is defined as $n$ and is expressed in Equation 8. The energy at interface II after $m$ th cycle, $E_{\mathrm{m}}$, is calculated using Equa-

Table 2 - Reflection Coefficients, Energy Absorptivity, Ratio of the Surplus Energy, and Energy Absorbed at the Faying Interface during Ultrasonic Welding

\begin{tabular}{cccccc} 
& $\gamma_{1}$ & $\gamma_{3}$ & $K$ & $n$ & $E_{2 \text { total }}\left(\mathrm{w} / \mathrm{mm}^{2}\right)$ \\
\hline CUSW & 0.383 & 0.732 & 0.257 & 0.195 & 1.4741 \\
HFUSW & 0.383 & $\approx 1$ & 0.293 & 0.267 & 1.842 \\
\hline
\end{tabular}

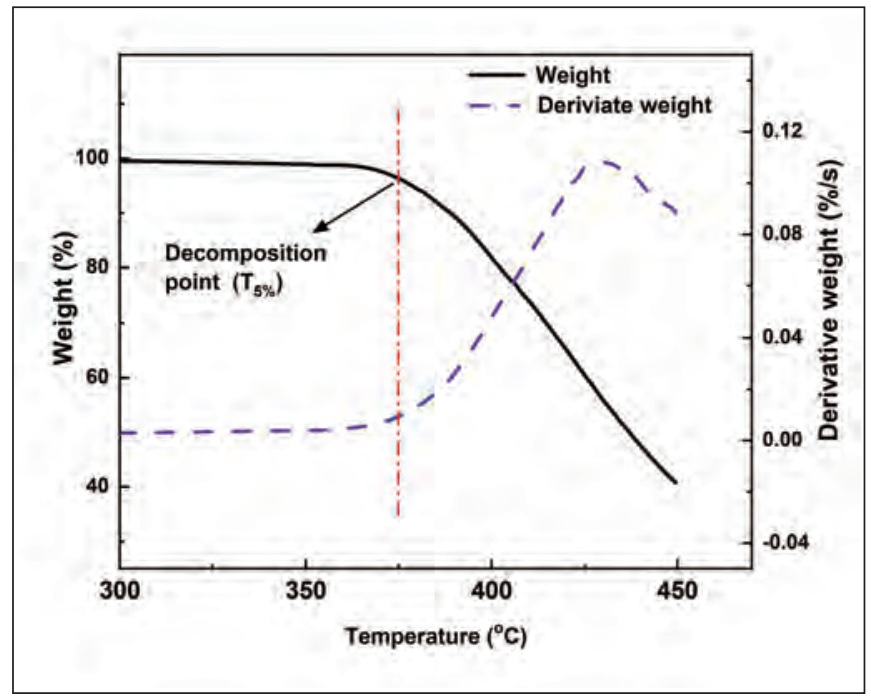

Fig. 7- Weight loss and derivative weight as a function of temperature for the carbon fiber/polyamide 66 composite.

tion 9. The total dissipated energy at interface II during the ultrasonic process can be obtained by Equation 10 .

$$
\begin{gathered}
n=E_{2-1} / E_{1}=e^{-8 \lambda X}(1-\alpha)^{2} \gamma_{1} \gamma_{3} \\
E_{\mathrm{m}}=n^{m-1} K E_{0}\left(1-\gamma_{1}-\alpha\right) \\
E_{2 \text { total }}=\sum_{1}^{\infty} E_{m}=E_{0} \frac{K\left(1-\gamma_{1}-\alpha\right)}{1=n}
\end{gathered}
$$

Based on the aforementioned equations, the reflection coefficients, energy absorptivity at interface II, and surplus energy were calculated. The results are listed in Table 2. It can be seen that the reflection coefficient at interface III during HFUSW, $\gamma_{3}$, was close to 1 , which means almost the total ultrasonic wave was reflected back to the workpieces. The energy absorptivity at interface II and the surplus energy, $K$ and $n$, were also larger for HFUSW. The energy absorbed at interface II for CUSW and HFUSW was 1.474 and $1.842 \mathrm{w} / \mathrm{mm}^{2}$, respectively. The dissipated energy at the faying interface dur- 


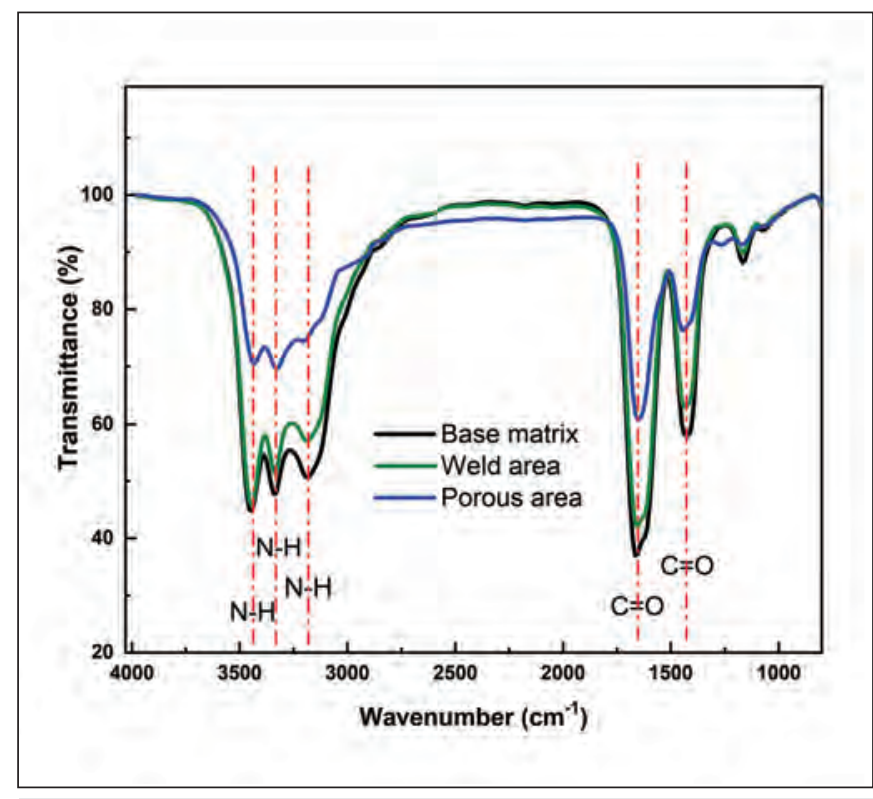

Fig. 8 - FTIR spectra of HFUSW joint welded in $2.5 \mathrm{~s}$.

ing HFUSW was about 25\% larger than that of CUSW under the same welding parameters, which implies that the energy efficiency in the HFUSW configuration was higher.

\section{Strengths of Ultrasonic Welded Joints}

The ultrasonic welded 4-mm-thick CF/PA66 composite joints with different fixture configurations were fabricated with various weld times at a weld pressure of $0.16 \mathrm{MPa}$, and the results are shown in Fig. 4. The peak loads of the HFUSW and CUSW joints increased first and then decreased as the weld time increased, and the increase/decrease velocities of the HFUSW joint were quicker than those of the CUSW joints, while the weld area increased and then approached a plateau. The optimal weld time for HFUSW was $1.7 \mathrm{~s}$ and $2.1 \mathrm{~s}$ for CUSW. It is interesting to find that the peak load of the HFUSW joint was higher than that of the CUSW joint when made with the same weld time (except for prolonged weld time, $\geq 2.5 \mathrm{~s}$ ).

To further understand the varying tendency of the peak load, the fracture surfaces of the joints after tensile testing were examined, as shown in Fig. 5. Referring to Fig. 5, the weld area increased as the weld time prolonged, and the porous regions occurred when weld time exceeded the optimal weld time (2.1 s for CUSW and $1.7 \mathrm{~s}$ for HFUSW). In addition, the entire weld area of the joint increased slightly, but the porous area increased quickly with the prolonged weld time. Based on other researchers' works (Refs. 21-23), the porous region mainly resulted from the thermal decomposition of the polymer. It can be indicated that the varying trend of the weld area in relation to the weld time was similar for CUSW and HFUSW joints, whereas it was quicker for HFUSW joints, validating the energy dissipation at the faying interface for HFUSW was higher than that of CUSW.

Visual examinations of the fracture surfaces also indicated there were two different failure modes, namely, interfacial failure and workpiece breakage. The joints fabricated with the optimal weld time, as well as those fabricated with less than the optimal weld time, were likely to display interfacial failure (i.e., 1.3, 1.7, $2.1 \mathrm{~s}$ for CUSW; 1.3, $1.7 \mathrm{~s}$ for HFUSW). By contrast, the joints welded over the optimal weld time (i.e., 2.5, $2.9 \mathrm{~s}$ for CUSW; 2.1, 2.5, $2.9 \mathrm{~s}$ for HFUSW) were likely to exhibit workpiece breakage regardless of the fixture configuration. Interfacial failure occurs mainly because the insufficient weld area cannot bear the tensile force and breaks through the nugget. When the weld area reaches the plateau, the fracture is likely to initiate from the edge of the weld area (i.e., the most stress-concentrated region) (Refs. 21, 24) and show workpiece breakage. As the porous area increases, the fracture may break through the porous region because severe decomposition deteriorated the workpiece.

As listed in Table 2, the energy dissipation at the faying interface for HFUSW was higher than that of CUSW; consequently, the peak load of the HFUSW joint was higher than that of the CUSW joint made with the same weld time. For the HFUSW joints made with the prolonged weld time (> 2.1 s), the peak load dropped quickly. This phenomenon is likely attributed to the decomposition of the composite (Refs. 21-23). The more energy that dissipates at interface II, the higher the temperature would be. Therefore, more composite decomposes and leaves a porous area, as shown in Fig. 5.

\section{Temperature Profile in Ultrasonic Welding}

To further understand weld formation during ultrasonic welding of 4-mm-thick CF/PA66 composite, temperature profiles near the faying interface for joints welded with their optimal weld time were measured and the results are shown in Fig. 6. Although the optimal weld time for the CUSW joint (i.e., $2.1 \mathrm{~s}$ ) was longer than that of the HFUSW joint (i.e., $1.7 \mathrm{~s}$ ), the highest transient temperature appeared in the HFUSW joint. In addition, the temperature increment rate in the HFUSW process was larger than that of CUSW; these characteristics are probably related with the ultrasonic wave transmission behavior. The quicker temperature increment in the HFUSW process is mainly because the ultrasonic energy density per second dissipated at interface II was larger, as described above.

The weight loss and derivative weight as a function of temperature is shown in Fig. 7. The material started to decompose at about $375^{\circ} \mathrm{C}\left(\mathrm{T}_{5 \%}\right)$, and the speed of weight loss increased with the increasing temperature. It is clear that the maximum temperature at the faying interface was higher than the decomposition temperature of the CF/PA66 composite. This high temperature during ultrasonic welding would probably cause the decomposition of the material and form a porous area at the faying interface. The FTIR spectra of the HFUSW joint welded with $2.5 \mathrm{~s}$ was recorded between 4000 and $400 \mathrm{~cm}^{-1}$ wavenumber, and the results are shown in Fig. 8. The fracture surface could be divided into three regions: the base matrix, weld area, and porous area, as shown in Fig. 5. In comparison with the base matrix, the absorption peaks of $-\mathrm{NH}$ and $\mathrm{C}=\mathrm{O}$ decreased slightly in intensity for the weld area and significantly for the porous area, which demonstrated the number of this functional group decreased (Ref. 25). Therefore, it can be inferred that the matrix decomposed severely at the porous region (Refs. 21, 26). The decomposition of the CF/PA66 released volatile gases 
and left pores in the composite, resulting in the porous region. Accordingly, the peak loads of the joints with a porous region decreased.

\section{Summary}

In this study, HFUSW was proposed, as it improved the energy efficiency at the faying interface. Modeling calculation results indicate that the energy dissipation at the faying interface in HFUSW was higher, by about $25 \%$, than that of the CUSW process under given welding parameters. Experimental results prove the energy absorption at the faying interface for HFUSW was higher than CUSW. In addition, the peak load of HFUSW joints was higher, and the optimal weld time shortened to $1.7 \mathrm{~s}$ from $2.1 \mathrm{~s}$ when compared with CUSW joints. This study demonstrates the HFSUW configuration has more advantages in energy efficiency and machine protection (ultrasonic transducer). The use of HFUSW would increase the design and structural flexibility of ultrasonic welded plastics. This study also provided a fundamental understanding of energy dissipation during ultrasonic welding of polymers.

\section{Conclusions}

1. Almost total reflection at the workpiece-to-fixture interface in HFUSW influenced the wave propagation and consequently enhanced the energy dissipation at the faying interface by about $25 \%$.

2. The optimal weld times for HFUSW and CUSW joints were 1.7 and $2.1 \mathrm{~s}$, respectively. The peak loads of HFUSW joints were higher when fabricated with optimal weld time.

3. The peak loads of the joints were related to the weld area for both HFUSW and CUSW. The decrease in peak load was mainly attributed to the occurrence of the porous area when weld time exceeded the optimal weld time.

4. The formation of the porous area was primarily because of the thermal decomposition of the composite.

\section{Acknowledgment}

This work was financially supported by the National Natural Science Foundation of China (Grant Nos. 51905167, 51775183, and 22008060), Natural Science Foundation of Hunan Province (Grant Nos. 2020JJ5197, 2019JJ50181, and 2020JJ5196), and Hunan Provincial Department of Education Project (19C0760).

\section{References}

1. Li, Y., Lin, Z., Jiang, A., and Chen, G. 2004. Experimental study of glass-fiber mat thermoplastic material impact properties and lightweight automobile body analysis. Materials \& Design 25(7): 579-585. DOI: 10.1016/j.matdes.2004.02.018

2. Amasawa, E., Hasegawa, M., Yokokawa, N., Sugiyama, H., and Hirao, M. 2020. Environmental performance of an electric vehicle composed of $47 \%$ polymers and polymer composites. Sustainable Materials and Technologies 25: e00189. DOI: 10.1016/j.susmat.

\section{0.e00189}

3. Fuchs, R. H. E., Field, R. F., Roth, R., and Kirchain, R. E. 2008. Strategic materials selection in the automobile body: Economic opportunities for polymer composite design. Composites Science and Technology 68(9): 1989-2002. DOI: 10.1016/j.compscitech. 2008.01.015

4. Xu, M. J., Liu, B. S., Zhao, Y. Q., Wang, Z. M., and Dong, Z. B. 2020. Direct joining of thermoplastic ABS to aluminium Alloy 6061-T6 using friction lap welding. Science and Technology of Welding and Joining 25(5): 391-397. DOI: 10.1080/13621718.2020. 1719304

5. Kim, J. H., Shin, P. S., Kwon, D. J., and Park, J. M. 2021. 2D electrical resistance (ER) mapping to detect damage for carbon fiber reinforced polyamide composites under tensile and flexure loading. Composites Science and Technology 201: 108480. DOI: 10.1016/j.compscitech.2020.108480

6. Peng, X., Zhang, M., Guo, Z., Sang, L., and Hou, W. B. 2020. Investigation of processing parameters on tensile performance for FDM-printed carbon fiber reinforced polyamide 6 composites. Composites Communications 22(8): 100478. DOI: 10.1016/j.coco. 2020.100478

7. Kunishima, T., Kurokawa, T., Arai, H., Fridricib, V., and Kapsa, P. 2004. Reactive extrusion mechanism, mechanical and tribological behavior of fiber reinforced polyamide 66 with added carbodiimide. Materials \& Design 188: 108447. DOI: 10.1016/ j.matdes.2019.108447

8. Li, Y., Yu, B., Wang, B., Lee, T. H., and Banu, M. 2020. Online quality inspection of ultrasonic composite welding by combining artificial intelligence technologies with welding process signatures. Materials \& Design 194: 108912. DOI: 10.1016/j.matdes.2020. 108912

9. Xie, J. L., Chen, Y. H., Yin, L. M., Zhang, T. M., Wang, S. L., and Wang, L. T. 2021. Microstructure and mechanical properties of ultrasonic spot welding TiNi/Ti6Al4V dissimilar materials using pure Al coating. Journal of Manufacturing Processes 64(1): 473-480. DOI: 10.1016/j.jmapro.2021.02.009

10. Wang, C. Y., Liu, H. H., Chen, Z. L., Zhao, D., and Wang, C. D. 2021. A new finite element model accounting for thermal contact conductance in laser transmission welding of thermoplastics. Infrared Physics \& Technology 112: 103598. DOI: 10.1016/j.infrared. 2020.103598

11. Kumar, R., Singh, R., Ahuja, I. P. S., and Fortunato, A. 2020. Thermo-mechanical investigations for the joining of thermoplastic composite structures via friction stir spot welding. Composite Structures 253(4): 112772. DOI: 10.1016/j.compstruct.2020.112772

12. Wang, S., and Lin, S. Y. 2019. Optimization on ultrasonic plastic welding systems based on two-dimensional phononic crystal. Ultrasonics 99: 105954. DOI: 10.1016/j.ultras.2019.105954

13. Ageorges, C., Ye, L., and Hou, M. 2001. Advances in fusion bonding techniques for joining thermoplastic matrix composites: A review. Composites Part A: Applied Science and Manufacturing 32(6): 837-857. DOI: 10.1016/S1359-835X(00)00166-4

14. Villegas, I. F. 2014. Strength development versus process data in ultrasonic welding of thermoplastic composites with flat energy directors and its application to the definition of optimum processing parameters. Composites Part A: Applied Science and Manufacturing 65: 27-37. DOI: 10.1016/j.compositesa.2014.05.019

15. Khmelev, V. N., Slivin, A. N., and Abramov, A. D. 2007. Model of process and calculation of energy for a heat generation of a welded joint at ultrasonic welding polymeric thermoplastic materials. $8^{\text {th }}$ Siberian Russian Workshop and Tutorial on Electron Devices and Materials: 316-322. DOI: 10.1109/SIBEDM.2007.4292995

16. Zhi, Q., Lu, L., Liu, Z. X., and Wang, P. C. 2018. Influence of horn misalignment on weld quality in ultrasonic welding of carbon fiber/polyamide 66 composite. Welding Journal 97(5): 133-s to 143-s. DOI: $10.29391 / 2018.97 .012$

17. Moguen, Y., and Dick, E. 2020. Diffusion and dissipation in acoustic propagation simulation by convection-pressure split algo- 
rithms in all Mach number form. Journal of Computational Physics 414(C): 109480. DOI: 10.1016/j.jcp.2020.109480

18. Wijk, H. V., Luiten, G. A., and Engen, P. G. V. 1996. Process optimization of ultrasonic welding. Polymer Engineering and Science 36: 1165-1176. DOI: 10.1002/pen.10510

19. Zhu, R., Liu, X. N., and Huang, G. L. 2015. Study of anomalous wave propagation and reflection in semi-infinite elastic metamaterials. Wave Motion 55: 73-83. DOI: 10.1016/ j.wavemoti. 2014.12.007

20. Gao, Y. H., Zhi, Q., Lu, L., Liu, Z. X., and Wang, P C. 2018. Ultrasonic welding of carbon fiber reinforced nylon 66 composite without energy director. Journal of Manufacturing Science and Engineering 140(5): 051009. DOI: 10.1115/1.4039113

21. Zhi, Q., Tan, X. R., Lu, L., Chen, L. Y., Li, J. C., and Liu, Z. X. 2017. Decomposition of ultrasonically welded carbon fiber/ polyamide 66 and its effect on weld quality. Welding in the World 61: 1017-1028. DOI: 10.1007/s40194-017-0482-5

22. Tolunay, M. N., Dawson, P. R., and Wang, K. K. 1983. Heating and bonding mechanisms in ultrasonic welding of thermoplastics. Polymer Engineering and Science 23(13): 726-733. DOI: 10.1002/ pen.760231307

23. Tao, W., Su, X., Wang, H. H., Zhang, Z. H., Li, H., and Chen, J. 2019. Influence mechanism of welding time and energy director to the thermoplastic composite joints by ultrasonic welding. Journal of Manufacturing Processes 37: 196-202. DOI: 10.1016/ j.jmapro.2018.11.002

24. Sung, S. J., and Pan, J. 2017. Accurate analytical structural stress and stress intensity factor solutions for similar and dissimilar spot welds in lap-shear specimens. Engineering Fracture Mechanics 182: 265-286. DOI: 10.1016/j.engfracmech.2017.07.032
25. Kundu, C. K., Li, Z. W., Li, X. H., Zhang, Z. J., and Hu, Y. 2020. Graphene oxide functionalized biomolecules for improved flame retardancy of polyamide 66 fabrics with intact physical properties. International Journal of Biological Macromolecules 156: 362-371. DOI: 10.1016/j.ijbiomac.2020.04.075

26. Liu, W., Zhang, S., Chen, X., Yu, L., Zhu, X., and Feng, Q. 2010. Thermal behavior and fire performance of nylon-6,6 fabric modified with acrylamide by photografting. Polymer Degradation and Stability 95: 1842-1848. DOI: 10.1016/j.polymdegradstab. 2010.04.023

QIAN ZHI, XINRONG TAN (tanxinrong0@163.com), WENHUI LIU, YANG LIU, BAOLI OU, and HONGWEI ZHAO are with the Hunan Provincial Key Laboratory of Advanced Materials for New Energy Storage and Conversion, Hunan Provincial Key Defense Laboratory of High Temperature Wear-Resisting Materials and Preparation Technology, Hunan Engineering Research Center of Forming Technology and Damage Resistance Evaluation for High Efficiency Light Alloy Components, Hunan University of Science and Technology, Xiangtan, China. ZHONGXIA LIU (liuzhongxia0@163.com) is with the School of Physics and Engineering, Zhengzhou University, Zhengzhou, China. PEICHUNG WANG is with the GM Global Technical Center, Warren, Mich.

\title{
Welding Journal Now Publishing Direct Object Identifier (DOI) Numbers
}

\author{
Dear members of the welding research community,
}

Note that in each issue of the Welding Journal Research Supplement, we are including Direct Object Identifier (DOI) numbers with each of the papers published in print and online. A DOI is a unique alphanumeric string assigned by a registration agency (we are using Crossref.org) to identify content and provide a persistent link to its location on the Internet. Our decision to begin assigning a DOI for each paper comes directly from a request by the research community.

As part of our obligation to Crossref.org, we are asked to provide DOI numbers, when available, in the references section of papers. So, if you have submitted a paper to the Welding Journal or are planning on submitting a paper, we ask that you update your references to include DOI numbers whenever possible.

Thank you.

Annette Alonso

Publisher, Welding Journal 